\title{
INTERAÇÃO DO CALCÁRIO E DO SILICATO DE CÁLCIO E MAGNÉSIO COM GESSO AGRÍCOLA NA PRODUÇÃO DE MASSA SECA DE Panicum maximum JACQ. CV. CAPIM MOMBAÇA
}

\author{
Vinícius Faúla Aguiar ${ }^{1}$ \\ Rosália Nazareth Rosa Trindade ${ }^{2}$ \\ Rodolfo Luiz Carvalhais Lima ${ }^{3}$ \\ Alisson José Eufrásio de Carvalho ${ }^{4}$
}

Resumo: O objetivo deste trabalho é avaliar o efeito das correções do solo efetuadas com calcário e silicato de cálcio e magnésio na produção de matéria seca de Panicum maximum Jacq. Cultivar capim Mombaça. Foi adotado delineamento o experimental em blocos ao acaso, em esquema fatorial $2 \times 5$, sendo estudado em quatro blocos o efeito de duas fontes de corretivo e cinco métodos de aplicação, além da testemunha. Nas análises onde foi observada significância estatística, realizou-se teste de Tukey a 5,0\% de probabilidade. A unidade experimental é constituída por vasos (colunas) de tubos de PVC de $15 \mathrm{~cm}$ de diâmetro por $60 \mathrm{~cm}$ de altura, totalizando 44 unidades. Para tanto, foi coletado solo do horizonte $B$ de barranco, com elevado teor de $\mathrm{A}^{3+}$. Para realização da massa seca foram realizados quatro cortes da forragem na altura de resíduo $(35 \mathrm{~cm})$. Os resultados encontrados para a variável massa seca de parte aérea indicaram o tratamento 08 como o que resultou em maior produção de forragem.

Palavras-chave: Casa de vegetação; Corretivo; Produção; Forragem.

\footnotetext{
1 Agronomia/Instituto Federal de Educação, Ciência e Tecnologia de Minas Gerais, Brasil, E-mail: vinicius.aguiar.agr@gmail.com.

2 Departamento de Engenharia Florestal/Universidade Federal dos Vales do Jequitinhonha e Mucuri, Brasil. Email: rosalia.trindade22@gmail.com.

3 Agronomia/Instituto Federal de Educação, Ciência e Tecnologia de Minas Gerais, Brasil, E-mail: rodolfocarvalhais93@gmail.com.

4 Agronomia/Instituto Federal de Educação, Ciência e Tecnologia de Minas Gerais, Brasil, E-mail: alisson.carvalho@ifmg.edu.br.
} 